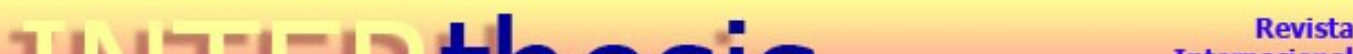 11NTERthesis $\ldots$ \\ INTERthesis
}

\section{SOUZA CRUZ: HISTÓRIA E IDEOLOGIA CONTEMPORÂNEA SOBRE RESPONSABILIDADE SOCIAL ${ }^{1}$}

\section{SOUZA CRUZ: HISTORY AND CONTEMPORARY IDEOLOGY ON SOCIAL RESPONSIBILITY}

\section{SOUZA CRUZ: HISTORIA E IDEOLOGÍA CONTEMPORÁNEA SOBRE RESPONSABILIDAD SOCIAL}

\author{
Sergio Luis Boeira ${ }^{2}$ \\ Camila Regina Cunha ${ }^{3}$
}

\section{RESUMO:}

Este artigo parte de uma pesquisa que teve como objetivo fazer um estudo sobre a história da Souza Cruz desde o seu surgimento em 1903 até o ano de 2007. O objetivo específico foi analisar o sentido histórico da ideologia da empresa sobre responsabilidade social e suas ambigüidades, inscritas nos projetos sociais da empresa. O referencial teórico-epistemológico combinou o paradigma da complexidade com a abordagem dos estudos críticos. A pesquisa foi documental e bibliográfica. Pretendeu-se contribuir com a administração pública brasileira no que se refere ao conhecimento sobre as complexas relações entre indústria de tabaco, efeitos socioambientais e saúde pública. Concluiu-se que a complementaridade entre o paradigma da complexidade e a abordagem dos estudos críticos permite compreender que a ideologia da Souza Cruz situa-se entre a stockholders theory e a stakeholders theory, de maneira ambivalente, e que ambas fazem parte do paradigma da simplificação (marcado pelo reducionismo e pela fragmentação).

Palavras-chave: Souza Cruz. Tabaco. Responsabilidade Social; Paradigmas.

\section{ABSTRACT:}

This article is based on a research which conducted a study about the history of Souza Cruz since its beginning that goes from 1903 until 2007. The specific objective was to analyze the historical sense of the ideology of the company on social responsibility and its ambiguities, inserted into social projects of the company. The

\footnotetext{
${ }^{1}$ Os autores agradecem ao CNPq o financiamento da pesquisa que serviu de base para este artigo.

2 Doutor em Ciências Humanas pelo Programa de Pós Graduação Interdisciplinar em Ciências Humanas da Universidade Federal de Santa Catarina (UFSC)e professor na Universidade do Vale do Itajaí (UNIVALI) entre 1996 e 2010. Desde 01/10/2010 é docente da UFSC, no Depto. de Administração. E-mail: sergio.l.boeira@redelnet.com.br

${ }^{3}$ Acadêmica do curso de graduação em Administração na Universidade do Vale do Itajaí (UNIVALI) E-mail: camilla.cunha@yahoo.com.br
} 
theoretical-epistemological perspective combined the paradigm of the complexity with the approach of critical studies. The research was documentary and bibliographic. This article aims to contribute with the Brazilian public administration regarding the knowledge about the complex relationships among the tobacco industry, environmental effects and public health. This study concluded that the complementarity between the paradigm of the complexity and the approach of critical studies demonstrates that the ideology of Souza Cruz about social responsibility is inserted between the stockholders' theory and the stakeholders' theory, in an ambivalent way, and that both are part of the paradigm of simplification (marked by reductionism and fragmentation).

Keywords: Souza Cruz. Tobacco; Social Responsibility; Paradigms.

\section{RESUMEN:}

Este artículo parte de una investigación que tuvo como objetivo hacer un estudio sobre la historia de la Souza Cruz desde su surgimiento en 1903, hasta el año de 2007. El objetivo específico fue analizar el sentido histórico de la ideología de la empresa sobre responsabilidad social y sus ambigüedades, inscritas en los proyectos sociales de la empresa. La referencia teórica y epistemológica combinó el paradigma de la complejidad con el abordaje de los estudios críticos. La investigación fue documental y bibliográfica. Se pretendió contribuir con la administración pública brasileña en lo que se refiere al conocimiento sobre las complejas relaciones entre industria de tabaco, efectos socioambientales y salud pública. Se concluyó que la complementariedad entre el paradigma de la complejidad y el abordaje de los estudios críticos permite comprender que la ideología de la Souza Cruz es parcialmente explicada por la stockholder theory y por la stakeholders theory, de manera ambivalente, y que ambas forman parte del paradigma de la simplificación (marcado por el reduccionismo y la fragmentación).

Palabras clave: Souza Cruz. Tabaco. Responsabilidad Social. Paradigmas.

\section{INTRODUÇÃO E ASPECTOS METODOLÓGICOS}

Em fevereiro de 2005 entrou em vigor o primeiro tratado internacional de saúde pública, conhecido como Convenção-Quadro de Controle do Tabaco (CQCT), depois de vários anos de negociações promovidas pela Organização Mundial da Saúde (OMS). Tal iniciativa é fruto de uma convergência de duas tendências mundiais: avanço dos processos democráticos e dos conhecimentos científicos. Mas é também plausível argumentar que o tratado internacional é resultante da constatação de que a globalização dos mercados tem favorecido os lucros das empresas do setor de tabaco (BRASIL, 2004).

De acordo com um Relatório da OMS (2008), o consumo de tabaco é um fator de risco para seis das oito principais causas de morte no mundo e mata uma pessoa a cada seis segundos. O "tabaco mata de um terço à metade de todas as pessoas que o usam, em média 15 anos prematuramente. Hoje o consumo de tabaco causa 
mais de cinco milhões de falecimentos ao ano" (OMS, 2008, p. 01). Isto justifica a iniciativa de um estudo sobre a ideologia da maior empresa do setor de tabaco no Brasil.

A problemática da responsabilidade social corporativa no caso da indústria de tabaco é debatida na literatura internacional (PALAZZO; RICHTER, 2005), reconhecendo-se suas peculiaridades e sua complexidade, mas sem uma abordagem teórico-epistemológica e crítica, como a que é proposta nesse artigo.

Quanto à CQCT, trata-se de grande relevância para o Brasil, já que o País é líder mundial em exportações de folhas de fumo, além de segundo maior produtor mundial. A região sul do Brasil é responsável por mais de $96 \%$ da produção nacional. De acordo com dados do IBGE, a cultura do fumo está presente em 682 municípios desta região: 147 no Paraná, 236 em Santa Catarina e 299 no Rio Grande do Sul (BIOLCHI, 2005). Estes municípios precisarão encontrar alternativas sustentáveis de produção à medida que a CQCT restringir o mercado comprador, especialmente América do Norte e Europa (BRASIL, 2004).

Neste contexto dramático e complexo, pergunta-se: como se desenvolveu a Sousa Cruz ao longo de sua história? Como, nessa história, surgiu e se afirmou a ideologia da responsabilidade social dessa empresa? Quais são as ambigüidades éticas e políticas desta ideologia? Cabe destacar que esta empresa é líder do mercado de derivados de tabaco no Brasil, além de um dos cinco maiores grupos privados no País, com ganhos líquidos em 2001 de quase $\mathrm{R} \$ 300$ milhões e vendas de US\$2,4 bilhões, atingindo $77,7 \%$ de participação no mercado interno (CORRÊA, 2004, p. 2). De acordo com o Guia Exame de Boa Cidadania Corporativa (GUIA EXAME 2004), esta empresa investe por ano mais de $\mathrm{R} \$ 4,2$ milhões em projetos sociais e ambientais.

Fez-se uma pesquisa bibliográfica e documental (artigos, dissertações e teses) em bibliotecas universitárias (especialmente da região Sul do Brasil), em anais de eventos acadêmicos, além de outras publicações da própria empresa (relatórios anuais, boletins trimestrais) e diversos materiais jornalísticos.

Para analisar e interpretar os textos foram considerados o paradigma da complexidade e a abordagem dos estudos críticos da administração. Quanto a esta última, Davel e Alcadipani (2003) propõem os seguintes critérios de seleção e análise de textos: a) visão desnaturalizada da administração; b) desvinculada da performance; c) intenção emancipatória. O primeiro critério permite reconhecer 
abordagens teóricas que revelam aspectos ideológicos à medida que as relações sociais são abstraídas do contexto histórico, o que é conhecido como naturalização. O segundo critério permite distinguir abordagens subordinadas aos interesses ou valores de mercado, como eficiência, eficácia e lucratividade, das contribuições críticas, desvinculadas da performance econômica. O terceiro critério permite reconhecer textos críticos à medida que destaca a intenção emancipatória, a promoção do "potencial da consciência humana para refletir de maneira crítica sobre as práticas opressivas, facilitando, assim, a extensão dos níveis de autonomia e responsabilidade das pessoas" (DAVEL; ALCADIPANI, 2003, p. 75).

É relevante destacar que este artigo não se limita a uma abordagem dual entre teoria e prática, nem é monodisciplinar ou multidisciplinar. De acordo com o pensamento complexo (interdisciplinar e transdisciplinar) de Edgar Morin (1991), elabora-se uma abordagem recursiva entre fenômenos, teoria e paradigma (ou metateoria). Isso implica em considerar as teorias como parte da problemática a ser compreendida.

Parte-se da hipótese de que falta no debate público uma abordagem crítica e metateórica (inter e transdisciplinar) da ideologia da responsabilidade social e das teorias dos stakeholders e dos stockholders, para que se conheça adequadamente as complexas relações entre indústria de tabaco, seus efeitos socioambientais e a saúde pública. Afinal, por quais razões diversos setores governamentais e diversas ONGs mantêm-se tolerantes e acríticos diante dos impactos negativos da indústria de tabaco?

Este artigo está estruturado da seguinte forma: na seção 1, apresenta-se o referencial teórico-epistemológico, incluindo-se conceitos de paradigma disjuntorredutor (ou da simplificação), paradigma da complexidade, racionalização, ideologia, teoria e racionalidade, além da distinção de três abordagens teórico-ideológicas da responsabilidade social das empresas. Na seção 2, descreve-se a história da Souza Cruz propondo-se uma distinção de três fases. Na seção 3, são sintetizadas algumas críticas de pesquisadores à ideologia da responsabilidade social da Souza Cruz e, por fim, apresentam-se as conclusões. 


\section{REFERENCIAL METATEÓRICO E TEÓRICO}

De acordo com o pensamento de Edgar Morin (1991; 1998; 2005) - há basicamente dois grandes paradigmas - embora cada um deles contenha paradigmas menores, vinculados a autores clássicos, metáforas (MORGAN, 2005) ou ciências particulares - em disputa no meio acadêmico contemporâneo: o disjuntor-redutor e o da complexidade.

A noção de paradigma é aqui utilizada como sinônimo de metateoria, por transcender qualquer teoria, permitir a reflexão sobre as teorias e sobre suas limitações. O primeiro paradigma, vinculado à revolução científica moderna, separa objeto e sujeito, qualidade e quantidade, estabelecendo polaridades no pensamento das sociedades urbano-industriais, com raízes históricas no século XVI (e mesmo antes), e favorecendo a emergência das chamadas ciências particulares, assim como o afastamento da filosofia em relação a todas as formas de ciência. Houve uma diáspora entre filosofia e ciências, que gerou mais tarde o que Postman denominou "tecnopólio", ou a rendição da cultura à tecnologia (POSTMAN, 1994). A cultura dita científica é separada das chamadas humanidades, pelo menos desde o cartesianismo, o que é reforçado pelo mecanicismo, pelo positivismo, pelo taylorismo, pelo funcionalismo e pelo estrutural-funcionalismo (MORIN, 1991).

O segundo grande paradigma - chamado da complexidade ou emergente se fundamenta, por um lado, na segunda revolução científica, ocorrida com a emergência da física quântica e subatômica na primeira metade do século $X X$, e, por outro, na terceira revolução científica, que se expressa pelos diálogos multi, inter e transdisciplinares, na busca de respostas a problemas crescentemente complexos e interligados pela própria dinâmica histórica. Enquanto o paradigma disjuntor-redutor

separa as formas de conhecimento ou as reduz a fórmulas abstratas e simplificadoras, o paradigma da complexidade associa sem fundir e distingue sem separar as diversas formas de conhecimento, contribuindo com uma percepção crítica, emancipadora e prudente da ciência (MORIN, 1998; 2005; VASCONCELOS, 2002; NICOLESCU, 1999). A vinculação entre o paradigma da complexidade e os estudos organizacionais ocorre por intermédio da perspectiva dos estudos críticos (ALVESSON; DEETZ, 1998; DAVEL; ALCADIPANI, 2003; BOEIRA; VIEIRA, 2006; ETKIN, 2003; MORGAN, 2005). A Interdisciplinaridade e a transdisciplinaridade são 
características fortes do pensamento complexo, que articula macroconceitos de diversas disciplinas e campos do conhecimento, não limitando-se às ciências sociais ou naturais. A obra de Morin, em especial, articula filosofia, antropologia, sociologia, história, cibernética, biologia, física, neurociências, teoria dos sistemas, teoria organizacional, etc. (MORIN; PIATELLI-PALMARINI, 1982; KOFMAN, 1996; FORTIN, 2005).

A perspectiva dos estudos críticos em administração (ECA) apresenta-se como uma das três principais abordagens dos chamados estudos organizacionais. Outras duas (entre as mais destacadas) são conhecidas como comportamento organizacional e estruturalista. Os estudos críticos buscam revelar algumas dimensões da análise organizacional não percebidas pelo paradigma disjuntorredutor. Esta perspectiva tem enfoque interdisciplinar e transdisciplinar. Trata de temas como gênero, conflito interétnico, poder, ideologia, ética e cultura (FRANÇA FILHO, 2004). A contribuição de Morgan (2005), contrapondo os paradigmas interpretativista, humanista radical e estruturalista radical ao paradigma funcionalista, é compatível com o paradigma da complexidade, tanto quanto a crítica de Clegg et al. (2004, p. 23) às "falácias da gestão estratégica" e a abordagem crítica de Chanlat (2000).

Da ideia de dimensões esquecidas pelo paradigma funcionalista, a abordagem de Chanlat (2000) avança para a noção de dimensões fundamentais nos estudos organizacionais. Em uma reflexão de duas décadas sobre as relações entre as ciências sociais e o management, Chanlat apresenta os seguintes temas emergentes no século XXI, que ele denomina de dimensões fundamentais: a) retorno do ator e do sujeito; b) retorno da afetividade; c) retorno da experiência vivida; d) retorno do simbólico; e) retorno da história; f) retorno da ética. Para Chanlat (2000), as organizações do século XXI têm como principais desafios a revisão do enquadramento do econômico no social e a preservação da natureza, a partir da reflexão ética.

Feita esta abordagem introdutória, será apresentada a seguir a perspectiva de Edgar Morin sobre a crise de paradigmas que atravessa o mundo contemporâneo, o que permitirá esclarecer termos centrais, como teoria e ideologia, racionalidade e racionalização. 


\subsection{Crise de Paradigmas: A Perspectiva de Edgar Morin}

A noção de paradigma no meio acadêmico tem evoluído, desde a conhecida obra de Thomas Kuhn (1962) sobre a estrutura das revoluções científicas, e nesse processo uma das contribuições mais significativas tem sido a de Edgar Morin. Enquanto em Kuhn a noção de paradigma é concebida como parte de comunidades científicas, em Morin a mesma é concebida como uma noção subjacente às visões de mundo que envolve as comunidades científicas, mas que não se limita às mesmas. Para este autor (1991, p. 188), "os indivíduos conhecem, pensam e agem segundo os paradigmas inscritos culturalmente neles. Os sistemas de idéias são radicalmente organizados em virtude dos paradigmas". ${ }^{4}$

Apresenta-se a seguir uma síntese das características básicas do paradigma disjuntor-redutor, que é dominante nas várias formas da ciência moderna, incluindo as ciências sociais, as ciências ditas naturais ou exatas. Para uma abordagem mais detalhada, recomenda-se consulta à obra do próprio Morin.

\section{Quadro 1: Síntese de Características do Paradigma Disjuntor-redutor}

a) Princípio de universalidade: só há ciência do geral. Expulsão do local e do singular como contingentes ou residuais;

b) Eliminação da irreversibilidade temporal, e, mais amplamente, de tudo o que é eventual e histórico;

c) Princípio que reduz o conhecimento dos conjuntos ou sistemas ao conhecimento das partes simples ou unidades elementares que os constituem;

d) Princípio que reduz o conhecimento das organizações aos princípios de ordem (leis, invariâncias, constâncias etc.), inerentes a essas organizações;

e) Princípio de causalidade linear, superior e exterior aos objetos;

f) Soberania explicativa absoluta da ordem, ou seja, determinismo universal e impecável. Assim, em função dos princípios a, b, c, d, e, a inteligibilidade de um fenômeno ou objeto complexo reduz-se ao conhecimento das leis gerais e necessárias que governam as unidades elementares de que é constituído;

g) Princípio de isolamento/separação do objeto em relação ao seu ambiente;

h) Princípio de separação absoluta entre o objeto e o sujeito que o percebe/concebe. A verificação por observadores / experimentadores diversos é suficiente não só para atingir a objetividade, mas também para excluir o sujeito cognoscente;

j) Eliminação de toda a problemática do sujeito no conhecimento científico;

k) Eliminação do ser e da existência por meio da quantificação e da formalização;

l) A autonomia não é concebível;

m) Princípio de confiabilidade absoluta na lógica para estabelecer a verdade intrínseca das teorias. Toda a contradição aparece necessariamente como erro;

n) Pensa-se inscrevendo ideias claras e distintas num discurso monológico.

Fonte: Adaptação a partir da obra de Morin (1998, p. 330, 331).

${ }^{4}$ Para uma análise comparativa das perspectivas de Kuhn e Morin sobre a noção de paradigma, ver Boeira e Koslowski (2009).

R. Inter. Interdisc. INTERthesis, Florianópolis, v.7, n.2, p. 276-315, jul/dez. 2010 
Após esta síntese das características do paradigma dominante, passa-se à síntese das características do paradigma da complexidade, tal como denominado por Morin.

\section{Quadro 2: Síntese das Características do Paradigma da Complexidade}

a) Princípio sistêmico ou organizacional: liga o conhecimento das partes ao conhecimento do todo. A ideia sistêmica é oposta à reducionista ("o todo é mais do que a soma das partes"). A organização do todo (átomo, partícula, órgão) produz qualidades novas em relação às partes consideradas isoladamente: as emergências. Mas o todo é também menos do que a soma das partes, cujas qualidades são inibidas pela organização do todo;

b) Princípio hologramático: coloca em evidência o aparente paradoxo dos sistemas complexos, nos quais não somente a parte está no todo, mas também este se inscreve nas partes.

c) Princípio do anel retroativo: rompe com o princípio de causalidade linear, na medida em que a causa age sobre o efeito e este sobre a causa. Inflacionistas ou estabilizadoras, as retroações são numerosas nos fenômenos econômicos, sociais, políticos, psicológicos ou ecológicos;

d) Princípio do anel recursivo: supera a noção de regulação com a de autoprodução e autoorganização. É um anel gerador, no qual os produtos e os efeitos são produtores e causadores daquilo que os produz. Os indivíduos humanos produzem a sociedade nas suas interações, mas a sociedade, enquanto todo emergente, produz a humanidade desses indivíduos fornecendo-lhes a linguagem e a cultura;

f) Princípio de auto-eco-organização (autonomia / dependência): os seres vivos são autoorganizadores, gastando para isso energia. Como têm necessidade de extrair energia, informação e organização no próprio meio ambiente, sua autonomia é inseparável dessa dependência - por isso é imperativo concebê-los como auto-eco-organizadores;

g) Princípio dialógico: une dois princípios ou noções que se excluem, embora permaneçam indissociáveis numa mesma realidade. Sob formas diversas, a dialógica entre ordem, desordem e organização, por meio de inumeráveis inter-retroações, está constantemente em ação nos mundos físico, biológico e humano.

h) Princípio da reintrodução daquele que conhece em todo conhecimento: esse princípio opera a restauração do sujeito nos processos de construção do conhecimento e ilumina a problemática cognitiva central - da percepção à formação de teorias científicas, todo conhecimento é uma reconstrução/tradução por um espírito/cérebro numa certa cultura e num determinado horizonte temporal.

Fonte: Adaptação a partir da obra de Morin (2000, p. 32 a 34).

\subsection{Ideologia e Racionalização versus Teoria e Racionalidade}

Para uma abordagem consistente da noção de ideologia, serão apresentadas a seguir, além de definições deste termo, alguns conceitos associados a este, como teoria, racionalidade e racionalização. Desta forma, procura-se aprofundar a abordagem sobre o confronto entre os paradigmas disjuntor-redutor e o da complexidade.

Classicamente, diversos autores contribuíram com concepções específicas de ideologia (Destutt de Tracy, Comte, Durkheim, Weber, Manheim, entre outros). Marx 
concebe a ideologia como um instrumento de dominação, que tem influência marcante nos jogos de poder e na manutenção dos privilégios que moldam a maneira de pensar e de agir dos indivíduos na sociedade. A ideologia, segundo Marx, é uma forma de conhecimento que mascara e encobre os conflitos sociais, especialmente os interesses de classe na sociedade capitalista (ARANHA; MARTINS, 1993).

Edgar Morin faz uma abordagem parcialmente diferente das noções de ideologia e teoria. Para ele ideologias são sistemas de idéias dotados de certa forma de vida.

\begin{abstract}
As ideologias nos possuem porque nós as possuímos: passamos a identificá-las conosco, com nossas necessidades, aspirações, esperanças, experiências, com nossas próprias vidas. Atacá-las, lesá-las, é prejudicar a nós mesmos. Assim, defendemos nossas idéias. Mas, reciprocamente, nossas ideologias se defendem por nosso intermédio (MORIN, 1986, p. 91).
\end{abstract}

Para o autor, todo sistema, inclusive o de idéias, tende, com o tempo, a degradar-se, corromper-se, desintegrar-se. Ele argumenta então que

contra essa entropia crescente, ele pode lutar pelo calor, isto é, pela atividade permanente de auto-revisão e auto-organização, através do intercâmbio com o mundo exterior e de diálogos com os outros sistemas de idéias (MORIN, 1986, p. 92).

Quando isto ocorre, diz Morin, a ideologia torna-se teoria, abre-se como sistema, ainda que apenas parcialmente. Ideologias tendem a fechar-se e petrificarse. Enquanto a teoria é concebida por ele como um sistema aberto, em princípio, mas que pode vir a fechar-se ideologicamente ao degradar-se, a ideologia é vista como um sistema em princípio tendencialmente fechado (com diferentes graus de fechamento - do mais próximo à teoria ao mais próximo da doutrina). Em vez do intercâmbio com os outros sistemas de idéias, as ideologias promovem apenas polêmica, refutação, rejeição, desqualificação moral dos oponentes. Afirmam-se a partir de suas idéias-chave e de seus princípios, que apresentam como evidências irrefutáveis. A ideologia torna-se não-falsificável (na expressão de Popper): não dispõe de nenhum meio de demonstrar a si própria a sua falsidade. A não falsificabilidade significa não-biodegradabilidade.

Tradicionalmente, teoria significa contemplação da realidade. Uma teoria articula conceitos, hipóteses, formas de racionalidade. É tanto mais consistente quanto mais está aberta aos testes ou dados empíricos, à argumentação lógica e ao 
contexto paradigmático (reconhecendo suas limitações paradigmáticas). Teorias são sistemas de idéias auto-exo-referentes, que aceitam críticas sob certas condições ou normas de comunidade/sociedade científica ou filosófica. Embora Morin conceba as teorias como sistemas de idéias abertos e as ideologias como sistemas de idéias fechados, ele considera que não existe uma ruptura exata entre os dois tipos de sistemas. Portanto, toda teoria tem aspectos ideológicos.

É razoável concluir, portanto, que ideologias são formas de conhecimento mais fechadas que as teorias e os paradigmas. As ideologias tendem a suprimir os dados que não são convenientes ao seu próprio reforço como sistema de idéias. Doutrinas e ideologias são sistemas de idéias auto-referentes, que recusam qualquer crítica. Servem como instrumento de poder de uns grupos sociais sobre outros, encobrindo as diferenças sociais, as peculiaridades das culturas e as relações de poder. "Estudar a ideologia é estudar as maneiras como o sentido serve para estabelecer e sustentar relações de dominação" (THOMPSON, 1995, p. 76).

Para complementar esta abordagem, será apresentada a seguir a diferenciação entre os conceitos de racionalidade e racionalização, na obra de Morin. Afirma o autor que

a razão não é uma qualidade, uma virtude da qual o homo sapiens seria
dotado pela sua própria natureza. A razão ou racionalidade é a aplicação de
princípios de coerência aos dados fornecidos pela experiência. A
racionalidade pode evoluir segundo os dados e segundo os princípios
organizadores do discurso (paradigmas). [...] A racionalidade não está [...]
só na coerência do edifício teórico procurado ou encontrado. Está na
vontade aberta de diálogo com a experiência e, mais extensamente, com o
mundo exterior. A verdadeira racionalidade supõe que o nosso saber não
esteja completo e que algo novo poderá modificá-lo (MORIN, 1986, p. 135,
136).

Enquanto na ciência "a racionalidade aberta dialoga com o acaso e o risco, a racionalização odeia o acaso porque ele a torna vulnerável" (Idem, p. 137). Ora, "o acaso não só enriquece a causalidade, ele impede que ela enlouqueça” (Idem, p. 137). A racionalização é "a coerência lógica que se constrói a partir de premissas incompletas ou erradas e/ou a partir de um princípio discursivo mutilador (o paradigma de disjunção- redução)". Ele complementa:

A racionalização caracteriza-se, ao mesmo tempo, por um excesso de lógica para com o empírico e pela rejeição da complexidade do real. Quer que o real obedeça às estruturas simplificadoras do espírito [...] (MORIN, 1986, p. 137). 
A racionalização ocorre tanto ao nível das teorias e ideologias quanto no nível da vida cotidiana egocêntrica, manifestando-se como autojustificativa, até chegar ao nível patológico. Assim, vê-se que o autor estabelece certa relação dual (embora não dicotômica) entre teoria (enquanto sistema aberto) e racionalidade, por um lado, e ideologia (enquanto sistema fechado) e racionalização, por outro. O paradigma da complexidade promoveria, segundo a perspectiva de Morin, a racionalidade e a teoria, enquanto o paradigma da disjunção-redução estaria contribuindo com a racionalização e a ideologia, ou seja, com o fechamento das idéias sobre si mesmas. Feitas estas distinções conceituais, passa-se agora à abordagem da ideologia da responsabilidade social das empresas.

\subsection{Ideologia da Responsabilidade Social das Empresas}

Há diferentes abordagens teórico-ideológicas da responsabilidade social das empresas, segundo as variações históricas e os interesses do empresariado, bem como dos estudiosos da temática. Serão apresentadas sinteticamente três das principais abordagens: a) escola socioeconômica ou pensamento cristão; b) teoria dos stockholders ou pensamento neoliberal; c) teoria dos stakeholders ou pensamento social-democrata.

A primeira destas é representada por Andrew Carnegie (1835-1919), que propunha uma responsabilidade pró-ativa dos mais afortunados junto aos menos afortunados (desempregados, deficientes físicos, doentes e idosos). Este era o princípio cristão da caridade, que deveria ser complementado pelo princípio da custódia, segundo o qual os ricos deveriam comportar-se como guardiões e multiplicadores da riqueza da sociedade. Uma outra vertente da escola socioeconômica é representada por Robert Ackerman que, em 1985, propôs a teoria da reatividade. Ao invés da forma pró-ativa, a responsabilidade social deveria ser compreendida como a capacidade da empresa de responder aos problemas sociais, o que ficou conhecido como "responsividade" (XAVIER; SOUZA, 2004, p. 3).

Elvisney Alves (2003) analisa a visão de Howard Bowen ao apresentar a origem da idéia de responsabilidade social da empresa. O trabalho de Bowen, intitulado Social Responsabilities of the Businesman, publicado em 1953 nos 
Estados Unidos e em 1957 no Brasil, foi patrocinado pelo Conselho Federal das Igrejas de Cristo da América. Em toda a primeira parte do século XX a percepção da temática da responsabilidade social das empresas estava muito vinculada ao perfil religioso e moral da sociedade norte-americana.

$\mathrm{Na}$ análise de Alves, o discurso de Bowen apresenta certa ambiguidade. Há um misto de obrigação e dever social relacionados com a integridade moral própria da época em questão. A vertente moral protestante se apresenta como defensora dos interesses individuais característicos da sociedade capitalista.

Cabe lembrar que a grave crise da década de 1930 desencadeou um processo de interferência do Estado na economia, traduzido inicialmente pelo New Deal e mais tarde pelo pensamento keynesiano, vinculado ao declínio dos ideais do livre-mercado. Alves (2003, p. 40) conclui que Bowen vincula as finalidades específicas dos homens de negócios a um "necessário esforço educacional prócapitalismo". A responsabilidade social da empresa pode evitar o "avanço desnecessário de regulamentações de controle do governo".

A segunda perspectiva, que de certa forma se contrapõe à da escola socioeconômica ou pensamento cristão, é representada principalmente pelo pensamento econômico neoliberal de Milton Friedman (1970), Prêmio Nobel de Economia em 1975. Para ele, a responsabilidade social da empresa é gerar lucros aos seus acionistas. A importância dos trabalhadores na organização estaria relacionada às suas contribuições para a riqueza dos acionistas e, assim, a melhoria da qualidade de vida dos operários estaria diretamente vinculada ao aumento dos lucros dos patrões, numa sociedade capitalista. Friedrich von Hayek (Prêmio Nobel de Economia, 1974) também atacou a "doutrina da moda" (fashionable doctrine) por atribuir quaisquer funções às empresas além da maximização do lucro no longo prazo. Levada às suas últimas consequências, essa tendência teria como resultado o aumento do poder das empresas, com efeitos política e socialmente imprevisíveis e indesejáveis, sobretudo se as grandes empresas passassem a determinar as prioridades sociais, econômicas ou políticas da sociedade (HAYEK, 1967). Outro autor internacionalmente conhecido, que defende a visão neoliberal, é Theodore Levitt (1958). Segundo ele, contrariando os postulados de Bowen, as corporações deveriam reconhecer as funções do governo e permitir que este cuidasse do bemestar social, de forma que elas pudessem cuidar dos aspectos materiais do bem- 
estar. A perspectiva de Friedman, Hayek e Levitt pode ser definida como stockholder capitalism, ou seja, capitalismo dos acionistas.

No artigo intitulado $A$ empresa socialmente responsável: o debate e as implicações, de Cláudio Machado Filho e Décio Zylbersztajn (2004), os autores partem da constatação de um confronto entre grupos de acadêmicos - os que defendem a stockholder theory e a dos defendem a stakeholders theory. Para os primeiros, a única responsabilidade social dos gestores de negócios é incrementar os lucros dos donos das organizações, sem fraudes nem enganos. Para os segundos, os gestores têm deveres para com diversos grupos - clientes, fornecedores, empregados, comunidade -, todos eles afetados pelas decisões da firma.

A terceira perspectiva, stakeholders theory ou pensamento social-democrata, contrapõe-se tanto ao viés filantrópico e paternalista da escola socieconômica quanto ao viés neoliberal. Quanto aos argumentos em defesa da teoria dos stakeholders, Freeman (1984), segundo Machado Filho e Zylbersztajn (2004), sustenta que a gestão envolve a alocação de recursos organizacionais e a consideração dos impactos dessa alocação em vários grupos de interesse dentro e fora da organização. O autor distingue entre stakeholders primários (acionistas e credores), que possuem direitos legais bem estabelecidos sobre os recursos organizacionais, e os stakeholders secundários (comunidade, funcionários, consumidores, entre outros), cujos direitos sobre os recursos organizacionais são apenas parcialmente estabelecidos em lei, sendo também em parte baseados em critérios de lealdade ou obrigações éticas. Esta teoria fundamenta-se na idéia de que o resultado final da atividade de uma dada organização deve levar em consideração os retornos que otimizam os resultados de todos os stakeholders envolvidos, e não apenas os dos acionistas.

A análise do debate entre a segunda e a terceira perspectivas permite elaborar dois modelos (tipos ideais weberianos) de capitalismo, conforme sugerido a seguir: 


\section{Quadro 3: Dois Tipos de Capitalismo}

\begin{tabular}{|c|c|}
\hline Stockholders capitalism (Friedman) & Stakeholders capitalism (Freeman) \\
\hline 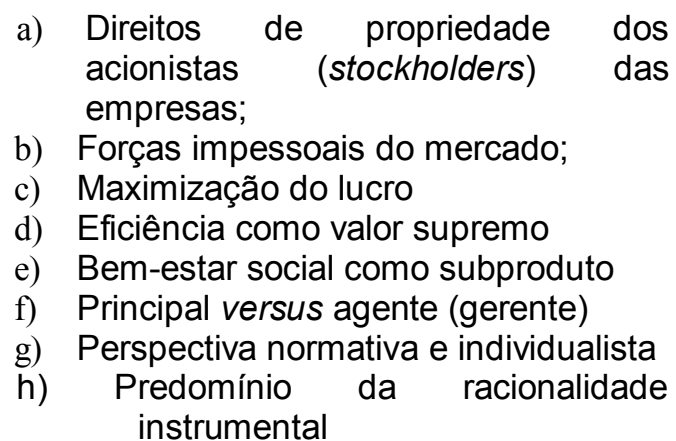 & $\begin{array}{l}\text { a) Responsabilidade corporativa diante de } \\
\text { todos os stakeholders } \\
\text { b) Desenvolvimento socioeconômico } \\
\text { c) Lucro com transparência e ética } \\
\text { d) Pluralismo em valores e objetivos } \\
\text { e) Busca de legitimidade da empresa } \\
\text { f) Socialização de riscos (parcerias) } \\
\text { g) Perspectiva realista e inclusiva } \\
\text { h) Predomínio da racionalidade } \\
\text { instrumental }\end{array}$ \\
\hline
\end{tabular}

Fonte: Adaptação a partir do artigo de Machado Filho e Zylbersztajn (2004).

Pena (2004) concentra sua contribuição no debate teórico sobre as limitações da ética da responsabilidade (WEBER, 1959) nas organizações como parte da teoria dos stakeholders. O autor afirma que a relação entre ética e estratégia deve ser objeto da seguinte pergunta: trata-se de uma estratégia organizacional que envolve a ética ou de uma ética organizacional que envolve a estratégia? E responde que, no âmbito de uma ética de negócios teoricamente bem articulada, somente a segunda opção deve ser aceita. O autor faz uma crítica às formas reducionistas pelas quais a ética tem sido abordada na maior parte dos estudos organizacionais.

É plausível concluir, com base na análise do confronto de argumentos acima, que a racionalização, a ideologia, ou razão instrumental predominam tanto na teoria dos stockholders quanto na teoria dos stakeholders. Os processos de certificação técnica da responsabilidade social, como a AccountAbility AA 1000 (1999), são igualmente limitados, reducionistas - encobrindo ideologicamente as contradições das empresas como forma de favorecer a sobrevivência e a gestão estratégica das mesmas. Isto é especialmente relevante no caso em questão, pois, conforme será visto adiante, a Souza Cruz passou a tomar a Norma AccountAbility (AA 1000) como ferramenta gerencial desde o ano 2001.

\section{FASES DA HISTÓRIA DA SOUZA CRUZ E FACES DE SUA IDEOLOGIA}

Nesta seção pretende-se, primeiramente, abordar aspectos da história da Souza Cruz, partindo-se de uma distinção de três fases. Em seguida, pretende-se 
abordar aspectos de programas sociais e temáticas que caracterizam as publicações da Souza Cruz. Depois disso, faz-se uma síntese de algumas contribuições de pesquisadores sobre a empresa.

\subsection{Três Fases Históricas e uma Interseção}

A indústria de cigarros afirma-se a partir do final do século XIX (com a invenção da máquina de confeccionar cigarros em 1881), sendo o setor dominado desde esse período pelas multinacionais estadunidenses e britânicas. Entre 1904 e 1947, as indústrias de tabaco dos EUA crescem tão ou mais rapidamente que as de carros. No Brasil, o chamado sistema integrado de produção de fumo foi criado em 1918, na região sul, pela British American Tobacco (BAT) - controladora acionária da Souza Cruz desde 1914 (OMS, 1992; BOEIRA, 2002; VOGT, 1997; SILVEIRA, 1997).

A história da Souza Cruz ocorre sob os dois últimos períodos do capitalismo ${ }^{5}$, aquele desencadeado no final do século XIX, e o que se constitui (particularmente entre os países centrais) a partir do final da década de 1960 e início dos anos 70 . Neste tópico, embora seja abordada a história da empresa desde seu surgimento, concentra-se a atenção nas fases que se inserem no período da globalização do capitalismo, visando explicitar as estratégias da indústria no contexto brasileiro nas últimas décadas.

Publicações sobre a empresa (SOUZA CRUZ, 1983; MORAIS, 2003) enfatizam a gestão carismática e a obstinação do seu fundador, o português Albino Souza Cruz, especialmente de 1903 a 1914. No Rio de Janeiro, em 25 de abril de 1903, Albino instala uma pequena fábrica com um grande avanço tecnológico para a época: cigarros enrolados em papel (SOUZA CRUZ, 1983). A iniciativa obtém sucesso imediato, pois até então a preparação dos cigarros dependia dos próprios consumidores, que usavam palha de milho para cobrir o tabaco. "Fumar cigarros enrolados em papel passou a ser sinônimo de elegância e modernidade" (MORAIS, 2003, p. 26). Em 1909, Albino faz um novo investimento: adquire uma chácara e

\footnotetext{
${ }^{5}$ A propósito da periodização do capitalismo, ver Boaventura de Sousa Santos (1995).
} 
prédios da Imperial Fábrica de Rapé Paulo Cordeiro, também no Rio de Janeiro, expandindo a produção de cigarros. A gestão carismática começa a declinar quando Albino se une a alguns colaboradores e funda a Souza Cruz \& Companhia, que em 1914 transforma-se em sociedade anônima e passa seu controle acionário à British American Tobacco. A nova empresa denomina-se Companhia Souza Cruz, recebe um forte suporte financeiro e a introdução de novas técnicas de fabricação, vendas e propaganda (SOUZA CRUZ, 1983). Tem início uma forma de gestão que mescla aspectos da burocracia com a da tecnocracia. Mas Albino Souza Cruz continua na presidência até o início da década de 1960 (MORAIS, 2003).

Enriquez (2007) define cinco tipos ideais weberianos de gestão: carismática, burocrática, tecnocrática, estratégica e cooperativo-dinâmica. Sob a primeira, a organização é a imagem do chefe, que é o ator principal. Toda a objeção, toda opinião contrária é considerada quase uma rebelião, pois o chefe carismático "se pensa infalível, tendo uma confiança total em seu próprio julgamento e em sua intuição" (ENRIQUEZ, 2007, p. 146). Este tipo de gestão não pode fazer uma "obra durável" (Idem, p. 146). Já no caso da gestão burocrática, não há mais chefe exemplar, transcendente, a ser imitado ou louvado. Gerentes assumem o poder com sua competência técnica, com autoridade racional, funcional, formal, impessoal e limitada. O "gestor está a serviço da organização-máquina que deve fazer funcionar da melhor maneira, como se ele mesmo fosse um rolamento da máquina" (Idem, p. 147). No caso da gestão tecnocrática, há experts (de economia, finanças, informática, biotecnologia, etc). De acordo com Enriquez, raramente o tecnocrata age só, normalmente faz parte de uma tecnoestrutura em que se agrupam experts das diferentes funções da organização. O gestor tecnocrata procede mais por sedução, por conselho, do que por ordens imperativas, utilizando técnicas de relações humanas "para manipular as inteligências e as psiques, bem como para integrar a maior parte dos trabalhadores" (Idem, p. 148).

A julgar pela história da Souza Cruz, houve uma mescla de aspectos da gestão burocrática com a da gestão tecnocrática na maior parte do século $X X$, de 1914 a meados da década de 1970. O ambiente competitivo e hostil desde então tem demandado um tipo de gestão que Enriquez define como estratégica: o estrategista, segundo ele, 
deve ser continuamente testado em um universo cada vez mais competitivo e conhecer bem as motivações, mesmo inconscientes, de seus colaboradores, para levá-los a trabalhar em uma equipe coesa e para extrair o máximo de cada um deles, que devem ser tomados pela "paixão da excelência'. Assim, além de seus conhecimentos técnicos (menos desenvolvidos que entre os tecnocratas), deve possuir os melhores métodos para seduzir seus colaboradores. Deve estar próximo deles, mesmo sendo exigente, e formar com eles uma verdadeira família. (ENRIQUEZ, 2007, p. 148).

Morais (2003, p. 95) informa que em 1970 a empresa começou a "substituir gradualmente os quadros dirigentes estrangeiros por jovens executivos saídos da universidade". O primeiro brasileiro a presidir a Souza Cruz é Antônio Monteiro de Castro Filho, em 1991. Isto ocorre no $88^{\circ}$ aniversário da corporação. Flávio de Andrade, o segundo brasileiro, o substitui em 1996: pela primeira vez, então, um fumante assume a presidência da empresa (MORAIS, 2003, p. 98).

Os projetos sociais tornam-se comuns desde a década de $1970 .{ }^{6}$ No contexto destes emerge a ideologia da responsabilidade social desta empresa que lidera o setor de fumo no país. De que forma a Souza Cruz mantém-se na liderança do mercado enquanto multiplicam-se as iniciativas contrárias ao tabagismo e em defesa do meio ambiente? O que faz para neutralizá-las? O que faz para ser vista como uma empresa moderna do ponto de vista social e ambiental? Quais são os seus projetos sociais e quanto investe nos mesmos? Estas questões são respondidas nos vários tópicos deste trabalho.

A hipótese de um capitalismo global recorta uma parte da realidade complexa que permeia e transcende todos os sistemas, do micro ao macrocosmo, inclusive o sistema global de Sklair (1995; SANTOS, 1995). A ideia de um paradigma da complexidade está subentendida aqui. Subordinada à hipótese de um capitalismo global aparece a ideia da "cultura-ideologia do consumismo" (SKLAIR, 1995), que por sua vez recebe um tratamento singular pela BAT, por intermédio de suas estratégias de marketing e do uso da tecnociência. O conceito de "política cognitiva" (RAMOS, 1981) vincula-se a uma interpretação crítica da sociedade centrada no mercado, algo que não se confunde com uma posição socialista ou meramente anticapitalista. Aspectos sociais, ambientais, culturais, políticos e econômicos entrelaçam-se nestes conceitos - particularmente considerando-se a multidimensionalidade e a interdependência do processo de globalização. A Souza

${ }^{6}$ Pouco antes de 1914, Albino Souza Cruz havia tomado "iniciativas como criar intervalos para o lanche e oferecer serviços médicos e farmacêuticos aos empregados" (MORAIS, 2003, p. 27).

R. Inter. Interdisc. INTERthesis, Florianópolis, v.7, n.2, p. 276-315, jul/dez. 2010 
Cruz aparece como um ator social complexo na medida em que lida com esta realidade multidimensional como empresa, tendo acumulado experiência em gestão tecnoburocrática na maior parte do século $X X$. Estrutura-se em forma de rede estratégica (BOEIRA, 2002; CLEGG et al., 2004). Este conceito expressa um conjunto de elementos (nós, elos, setores) que têm uma vinculação (linha) com um elemento central ou predominante. Por meio desse vínculo há um fluxo de informações ou ordens que geram um movimento estratégico-sistêmico mais ou menos complexo, mais ou menos mecanicista. Quanto mais unidirecionais são os fluxos do centro para a periferia - mais mecanicista é a rede. A sede da BAT em Londres ocupa uma posição estratégica na coordenação das decisões de investimentos de todo o grupo, incluindo a Souza Cruz, no mercado global, sendo que na América Latina esta última desempenha um papel estratégico para o grupo. No âmbito nacional, este papel em relação ao conjunto das empresas do setor cabe, até certo ponto, à ABIFUMO (Associação Brasileira da Indústria do Fumo), mas com forte peso da Souza Cruz. A razão instrumental e tecnocientífica é marcante no modelo de rede estratégica. No entanto, quanto mais houver intercâmbio pluridirecional (centro-periferia e entre os elementos da periferia) - mais complexo é este modelo, já que ordem e desordem interagem gerando continuamente reorganização. A $3^{a}$ Revolução Industrial permite interações face a face via eletrônica, anulação da distância física, desterritorialidade, multiplicação de consultas administrativas, maior transparência controlada dos processos produtivos, eliminação de cargos intermediários, etc. O ambiente (eco) é mero cenário nas interações mecanicistas e uma fonte de informações (neguentropia) na medida em que a rede se complexifica. $\mathrm{O}$ ambiente, neste caso, pode ser tanto um ecossistema quanto um concorrente ou um grupo de oposição (antitabagista, ambientalista).

Embora a história da Souza Cruz tenha relações com dois períodos do capitalismo, pode-se detectar três fases mais relevantes, incluindo uma superposição ou interseção entre as duas primeiras. Os 75 anos iniciais da empresa são marcados pelo pioneirismo tecnológico, pela gestão tecnoburocrática e por um rápido crescimento em âmbito nacional. Destaca-se o aspecto mecanicista da rede estratégica em formação.

De 1903, data de construção da primeira unidade de produção de cigarros, no Rio de Janeiro, até 1978, ano em que inaugura a maior fábrica de cigarros da América Latina, em Uberlândia (MG), a companhia notabiliza-se por sua expansão 
geográfica, com abertura de filiais em todo o Brasil (SOUZA CRUZ, 1983; MORAIS, 2003). A fase seguinte - que acentua tendência iniciada em 1972 e vai até 1991 caracteriza-se por investimentos em diversificação de empreendimentos, exportação de fumo em folha e crise do estilo de administração tecnoburocrática (característico do período de capitalismo organizado), com fechamento de várias unidades industriais e de vendas. Nesta fase também são iniciados programas socioambientais, como o Clube da Árvore e o Hortas Escolares, sinalizando a emergência de uma maior complexidade na rede estratégica.

A partir de 1991 tem início a fase contemporânea, marcada pela reconcentração no setor de tabaco, pela reação ao antitabagismo e pela retomada dos investimentos em modernização tecnológica, com inauguração da maior usina de beneficiamento de fumo do mundo em 1996, em Santa Cruz do Sul (RS), e a abertura de nova fábrica de cigarros em 1997, na Grande Porto Alegre. A empresa, neste mesmo ano, define sua política ambiental, de segurança e saúde ocupacional, o que, juntamente com os programas socioambientais e a reação ao antitabagismo, revela um processo complexo que envolve autoconfronto e crescente ambigüidade institucional, característico da modernização reflexiva e do processo de globalização capitalista.

Nos anos 90 a Souza Cruz adapta-se à globalização da economia, reestruturando sua forma de administração (com muitas demissões) e modernizando tecnologicamente o sistema integrado de produção na região sul do Brasil, pelo qual busca controlar o padrão de qualidade e a quantidade de tabaco. Este processo ocorre sob a coordenação da BAT, tendo como base a tecnologia da informação, a padronização de equipamentos e peças de reposição, racionalização dos processos de abastecimento de cigarros e fumo em folha, integração das técnicas de marketing e defesa jurídica. Surgem processos judiciais contra a indústria do fumo em vários países, incluindo o Brasil.

Em síntese, um perfil da indústria de tabaco na modernidade, no período do capitalismo dito "organizado" (SANTOS, 1995, p. 79), inclui expansão legal e ilegal, apesar da (e inclusive devido à) repressão. As empresas ganham mercado absorvendo as críticas antitabagistas, como no caso do lançamento do cigarro com filtro (GLANTZ et al, 1996).

No Brasil, enquanto a produção de fumo no século XIX se caracteriza pela desconcentração - ainda que com o predomínio da Bahia sobre as demais regiões 
-, no século $X X$ a crescente concentração na região sul é a característica mais relevante (NARDI, 1996; VOGT, 1997). E é no centro do Rio Grande do Sul, com a colonização alemã, que nasce o núcleo que viria a ser atualmente a capital do fumo: Santa Cruz do Sul. O chamado sistema integrado de produção de fumo é base do sucesso do setor no Brasil.

O estabelecimento do sistema integrado de produção de fumo foi resultado de uma bem articulada estratégia de marketing, baseada em conhecimentos tecnocientíficos e etnográficos. Alguns destes são apontados por dirigentes da BAT: a) adequação das terras da região ao cultivo do fumo de estufa, com clima moderado e chuvas bem distribuídas durante as fases do ano; b) tradição de produção familiar em pequenas propriedades; c) perfil cultural dos colonos: dedicados, caprichosos; d) consolidação do cultivo e do comércio do produto na região; e) existência de estrada de ferro como meio de transporte (VOGT, 1997).

Os colonos, de fregueses dos comerciantes, passam à condição de fregueses das agroindústrias, com "perda de autonomia no processo de trabalho dos produtores familiares de tabaco" (VOGT, 1997, p. 108; PAULILO, 1990). Isto ocorre à medida que as empresas, seguindo o exemplo da BAT/Souza Cruz, passam a fornecer, como forma de adiantamento, as sementes e os fertilizantes, além de financiar a construção das estufas. As sementes de fumo virgínia, importadas dos EUA, são introduzidas sistematicamente com o objetivo de expandir a produção de cigarros, cujo mercado rapidamente superava o dos demais derivados de tabaco (conseqüência da industrialização). Esse tipo de fumo, entretanto, também representa uma intensificação no processo de desmatamento e derrubada de florestas, já que requer, para a secagem das folhas, a construção de estufas (galpões de madeira) e o uso de lenha como combustível (por ser este considerado o mais barato e de mais fácil acesso). Durante 60 anos de expansão do cultivo de fumo virgínia, o aspecto predatório deste sistema produtivo permanece praticamente sem qualquer questionamento. É somente ao final dos anos 70 que a Souza Cruz mostra alguma preocupação com a exaustão das matas nativas (RODRÍGUEZ, 1996; BOEIRA, 2002; ALMEIDA, 2005).

O Brasil assume a liderança na exportação de tabaco no mundo desde 1993, em grande medida devido ao sistema de integração da produção de fumo à lógica industrializante. De 1980 a 2003, aumenta em 70\% a produção brasileira, 
assumindo a segunda posição em 2002. Em primeiro lugar está a China, em terceiro a Índia, em quarto os Estados Unidos.

\subsection{Projetos Sociais, Culturais e Ambientais: Faces da Ideologia Empresarial}

A Souza Cruz investe mais de quatro milhões por ano em projetos sociais, culturais e ambientais, segundo o Guia Exame 2004. Neste sentido, a teoria dos stakeholders parece destacar-se em relação à teoria dos stockholders na busca de compreensão das estratégias empresariais. Em contrapartida, nos últimos anos são publicadas obras críticas da ideologia da responsabilidade social da empresa (PINCELLI, 2005; CORRÊA, 2004; JOHNS; MONTEIRO, 2005). Na abordagem do paradigma da complexidade e dos estudos críticos da administração, as duas teorias são limitadas pelo paradigma disjuntor-redutor e ambivalentes, tanto contribuindo com a compreensão da realidade da empresa quanto encobrindo parcialmente a complexidade de tal realidade.

$\mathrm{Na}$ seqüência apresentamos as categorias dos projetos, a quantidade, a modalidade (em parceria com outras empresas, com órgãos governamentais, com entidades civis ou de forma independente) e o investimento anual da empresa: a) geração de renda: dois, em parceria, $R \$ 320.000,00$; b) cultura: um, em parceria, $R \$ 110.000,00)$; financiamento de projetos: um, independente, $R \$ 115.000,00 ; c)$ meio ambiente: três, sendo um deles em parceria; $R \$ 575.000,00 ; d)$ criança e adolescente: três, sendo dois deles em parceria; $R$ \$ 1.395.000, 00; e) educação: três, sendo dois em parceria; $\mathrm{R} \$$ 1.743. 000,00. Portanto, os tipos de projetos em que a empresa mais investe são os de educação e os que tratam de criança e adolescente (GUIA EXAME, 2004).

O website do Instituto Souza Cruz (2004) é intitulado Educação para o desenvolvimento humano sustentável. ${ }^{7}$ Nele a empresa afirma optar por "Investimento Social Corporativo" em vez de "filantropia", por ser esta tradicionalmente vista como "atividade caridosa, independente dos valores, práticas e identidade dos negócios da companhia". A empresa define este tipo de

\footnotetext{
${ }^{7}$ Maiores informações ver em: http://www.institutosouzacruz.org.br/ .
}

R. Inter. Interdisc. INTERthesis, Florianópolis, v.7, n.2, p. 276-315, jul/dez. 2010 
investimento como qualquer atividade voluntária - em espécie ou em produtos que vai "além das nossas obrigações legais e comerciais e que contribuem para a sustentabilidade econômica, social e ambiental dos países e comunidades onde temos operações" (INSTITUTO SOUZA CRUZ, 2004). ${ }^{8}$

Além disso, a empresa afirma que o grupo British American Tobacco adota três temas globais para o Investimento Social Corporativo: Agricultura Sustentável, Desenvolvimento Social e Participação Cidadã. Afirma também que "como empresa cidadã responsável acreditamos que devemos ser julgados por nossas ações e impactos ao invés de simplesmente por nossas intenções" (INSTITUTO SOUZA CRUZ, 2004). ${ }^{9}$ Por falar em impacto, cabe lembrar que o maior impacto causado pela indústria de tabaco é sem dúvida um conjunto de doenças e mortes, além de degradação ambiental. Justamente por esse motivo é que o primeiro tratado internacional de saúde pública aborda o controle global do tabaco. ${ }^{10}$

No mesmo website do Instituto a empresa aponta suas atividades de acordo com os três temas globais da BAT. No que se refere à agricultura sustentável, a empresa observa que é uma das principais compradoras de fumo no Brasil, com 40.000 produtores rurais envolvidos no sistema de produção integrada. A Souza Cruz também informa ter implementado um processo de diálogo no Departamento de Fumo com base na Norma AA 1000, levando em consideração as expectativas dos seus principais stakeholders na área do fumo, decidindo, como consequência disso, investir no uso racional da água, no aprimoramento dos produtos rurais, em segurança, em programas de organizações e limpeza das pequenas propriedades agrícolas, em atividades de certificação de tais propriedades, na implementação do programa O futuro é agora para a erradicação do trabalho infantil, na redução do uso de pesticidas e no desenvolvimento dos Centros de Desenvolvimento de Jovens Rurais (CEDEJOR).

\footnotetext{
${ }^{8}$ Muitas informações aqui resumidas estão detalhadas no Relatório de Atividades 2006 (SOUZA CRUZ, 2006), documento encontrado no website da empresa: www.souzacruz.com.br .

${ }^{9}$ Schnapper (1996, p. p. 100) analisa os limites da expressão empresa cidadã. Ele afirma na conclusão que "a empresa oferece aos cidadãos, essencialmente graças à sua actividade e ao seu êxito, as condições para o exercício da cidadania. Mas não a substitui e, em si mesma, não é cidadã". ${ }^{10}$ Cerca de 24,6 milhões de brasileiros de 15 anos ou mais de idade fumavam derivados de tabaco em 2008 , o que correspondia a $17,2 \%$ da população nessa faixa etária. Os percentuais de fumantes eram maiores entre os homens $(21,6 \%)$, entre as pessoas de 45 a 64 anos de idade $(22,7 \%)$, entre os moradores da região Sul do país $(19,0 \%)$, os que viviam na área rural $(20,4 \%)$, os menos escolarizados $(25,0 \%$ entre os sem instrução ou com menos de um ano de estudo) e os de menor rendimento domiciliar per capita $(19,9 \%$ entre os sem rendimento ou com menos de $1 / 4$ de salário mínimo). A maior parte deles começou a fumar com 17 a 19 anos de idade (IBGE/PETAB, 2008).
} 
É de grande relevância a seguinte informação da Souza Cruz, apresentada no mesmo website:

Todas estas atividades buscam aumentar a produtividade e competitividade dos produtores rurais associados com a Souza Cruz, e assim assegurar uma sustentabilidade a longo prazo do negócio do tabaco, administrando de forma eficiente os impactos da fumicultura no meio ambiente (INSTITUTO SOUZA CRUZ, 2004).

Quanto ao segundo tema adotado pela BAT, desenvolvimento local, a empresa começa informando que "possui" cerca de 210.000 varejistas, 40.000 produtores rurais e centenas de transportadoras. Diz que se "esforça" para que sua cadeia de suprimentos esteja em conformidade com os princípios de Responsabilidade Social. Em seguida, a empresa informa que, no contato com seus principais stakeholders, recebe

várias solicitações para atender às demandas de organizações de
assistência social que necessitam de veículos, equipamentos de
informática, livros e pessoas para fazer trabalho voluntário em áreas
extremamente pobres, onde a Souza Cruz opera seus negócios. Como
consequência disso, a Souza Cruz desenvolveu um programa chamado
Frota Social, que já doou 320 veículos usados para organizações de
assistência, e também implementou o programa de Inclusão Digital, cujo
objetivo é doar equipamentos de informática para escolas e centros
profissionalizantes, totalizando 267 computadores até a presente data. A
Souza Cruz estimula o trabalho voluntário entre seus funcionários, com o
programa Voluntários Souza Cruz (INSTITUTO SOUZA CRUZ, 2004).

Quanto ao terceiro tema global da BAT, participação cidadã, a empresa informa que tem participado de seminários relacionados à Governança Corporativa, Responsabilidade Social Corporativa, Ética Organizacional e Empreendedorismo Rural. Informa também que seus funcionários participam destas atividades como difusores dos conceitos de cidadania corporativa e civil. Como resultado dos diálogos com os principais stakeholders, a empresa desenvolveu os Diálogos Universitários, um "programa que apresenta a empresa, seus negócios e sua responsabilidade social corporativa". Além disso, um "consultor externo faz apresentações sobre tópicos escolhidos pelos alunos da universidade" (INSTITUTO SOUZA CRUZ, 2004).

Ainda quanto ao mesmo tema global, a empresa diz que "através do CEDEJOR" promove o desenvolvimento de projetos empresariais rurais nos três estados que produzem fumo no sul do Brasil: Paraná, Santa Catarina e Rio Grande do Sul" (INSTITUTO SOUZA CRUZ, 2004). A empresa também afirma desenvolver projetos sobre a prevenção do acesso de jovens menores de 18 anos ao cigarro, 
através do programa chamado "Responsabilidade Social Aqui Tem, que distribuiu 35.000 adesivos em pontos de vendas do Rio Grande do Sul, em Belo Horizonte e em Brasília, esperando chegar a 210.000 varejistas" (INSTITUTO SOUZA CRUZ, 2004). Informa também que os direitos autorais para usar o programa Cuidar, cujo objetivo é fazer os jovens mais conscientes dos comportamentos de risco, foram cedidos ao Instituto Ayrton Senna.

\subsubsection{Instituto Souza Cruz e Revista Marco Social}

No ano 2000 a empresa cria o Instituto Souza Cruz e a revista Marco Social, dois veículos de promoção da ideologia da responsabilidade social. O Instituto Souza Cruz foi criado em julho, no Rio de Janeiro, como organização nãogovernamental, sem fins lucrativos, reconhecido pelo Ministério da Justiça como OSCIP (Organização da Sociedade Civil de Interesse Público). Sua causa central declarada é a Educação para o Desenvolvimento Humano Sustentável. Inicialmente, assume a herança da empresa em termos de iniciativas sociais e ambientais de décadas anteriores. O Instituto

\footnotetext{
busca criar condições para que pessoas, grupos, organizações e comunidades possam adquirir conhecimentos, valores, atitudes e habilidades que lhes permitam se situar perante sua realidade e atuar sobre ela de maneira solidária, produtiva, criativa e transformadora (INSTITUTO SOUZA CRUZ, 2004).
}

A partir de 2004, o Instituto concentra-se no jovem rural como público-alvo prioritário. O programa principal é o Empreendedorismo do Jovem Rural, implementado no âmbito da parceria com os Centros de Desenvolvimento do Jovem Rural (CEDEJOR), nos três estados do Sul do país. O objetivo é incentivar processos "sustentáveis através da formação de jovens empreendedores, com senso de responsabilidade e capacidade de autogestão, aptos a exercer papel de liderança e inovação no desenvolvimento local" (INSTITUTO SOUZA CRUZ, 2004).

Ao focalizar sua atenção no jovem rural, o Instituto pretende obter mais eficiência na aplicação de recursos e nos esforços de formação. "A escolha de um público-alvo prioritário também permite ao Instituto trilhar um caminho consistente em busca de resultados mensuráveis e cada vez mais relevantes para a sociedade" 
(INSTITUTO SOUZA CRUZ, 2004). A justificativa para tanto é a de que os jovens do meio rural não têm sido suficientemente atendidos pelas políticas públicas, embora tenham potencial para se tornar "agentes de desenvolvimento". O principal desafio do Instituto é

\begin{abstract}
trabalhar para que o desenvolvimento do jovem rural seja também o objetivo de um crescente número de pessoas e organizações. A meta é convencer e mobilizar os diversos segmentos dos setores público e privado a aderirem à ideia de que a preparação das pessoas do campo para o desafios do mundo moderno depende da educação que lhes é oferecida (INSTITUTO SOUZA CRUZ, 2004).
\end{abstract}

A revista Marco Social também é criada em julho de 2000 com a temática Empresa, Ética e Cidadania. A concepção editorial é de um pedagogo. Entre as organizações em destaque na edição estão GIFE, ABRINQ, ACESITA, ODEBRECHT e a Rede Globo de Televisão. A revista promove divulgação de projetos de outras organizações, com isso favorecendo parcerias e melhoria da imagem social da Souza Cruz.

A segunda edição, em maio de 2001, destaca o tema Empreendedorismo do Jovem Rural. Diversos especialistas tratam de capital social e desenvolvimento, sustentabilidade das pequenas propriedades e a educação rural. Destacam-se experiências como a Casa Familiar Rural, o MEPES (Movimento de Educação Promocional do Espírito Santo) e o ProJovem.

A terceira edição da revista, em novembro de 2001, destaca o tema Educação para o Meio Ambiente. Apresenta reflexão de alguns intelectuais e experiências de organizações que tratam de educação ambiental e outras questões ligadas à problemática ecológica.

A quarta edição da revista, em julho de 2002, destaca o tema Educação para o Turismo. Abre espaço para especialistas abordarem diversos aspectos do turismo no país. Também apresenta reportagens sobre experiências governamentais e não governamentais.

A quinta edição, de janeiro de 2003, destaca o tema Educação para Valores. Apresenta iniciativas do Instituto e artigos de intelectuais sobre ética, desigualdade social, educação, entre outros temas.

Temáticas semelhantes aparecem nas vinte e sete (27) edições do Boletim do Instituto, até junho de 2007 , todas disponíveis no referido website. A primeira foi publicada em julho/agosto de 2001, com um balanço das atividades do primeiro ano 
do Instituto. As edições subsequentes abordam aspectos dos programas da Souza Cruz, entrevistas com lideranças de organizações, com especialistas de várias universidades ou órgãos governamentais, estimulando parcerias e, assim, socializando uma imagem positiva da Souza Cruz, como empresa aberta ao diálogo e interessada nos bens públicos.

\subsubsection{AccountAbility 1000: Estratégia e Ideologia da Souza Cruz}

Em sua dissertação intitulada O processo de accountability como estratégia de negócio: o caso Souza Cruz e a implantação da norma AA 1000, Aversa (2006) informa que a empresa é pioneira e única (até 2006) a utilizar no Brasil esta norma como estratégia - desde o ano 2001.

Karkotli e Aragão (2004) consideram a Norma AA 1000 como um dos indicadores de responsabilidade social, e não como uma estratégia. Os demais indicadores, segundo eles, seriam o Balanço Social, a Norma SA 8000, o Global Compact e os Indicadores Ethos.

A Norma AA 1000 é apresentada por Karkotli e Aragão (2004, p. 113) também como uma "ferramenta que poderá auxiliar a organização na identificação, aperfeiçoamento e comunicação das práticas de responsabilidade social". O termo "ferramenta" acentua o aspecto instrumental da racionalidade envolvida, ou seja, seu processo racionalizador, tendende a fechar-se num sistema de idéias, numa ideologia, conforme conceito visto anteriormente. Cabe ressaltar: tanto na interpretação de Aversa quanto na interpretação de Karkotli e Aragão, a Norma $A A$ 1000 é vista como um instrumento (estratégia instrumental ou indicador técnico), o que caracteriza suas abordagens como subordinadas ao paradigma disjuntorredutor. Esta observação também ressalta a relevância de uma abordagem metateórica ou paradigmática.

A Norma $A A 1000$ foi desenvolvida em 1998 pelo Institute of Social and Ethical Accountability (ISEA), organização não-governamental com sede em Londres, que tem como missão "promover e dar suporte às organizações nas atividades de implementação de sistemas de gestão éticos e socialmente 
responsáveis" (KARKOTLI; ARAGÃO, 2004, p. 114; ACCOUNTABILITY 1000, 1999).

Quais as vantagens da empresa na adoção da $A A 1000$ ? Os autores apontam as seguintes:

a) permite a avaliação por indicadores-chave do desempenho social; b) melhora a gestão da qualidade nos relacionamentos com os stakeholders; c) promove o relacionamento com trabalhadores; d) melhora a confiança de stakeholders externos; e) melhora e ajuda a manter boas relações de parceria; f) proporciona suporte de gestão à organização; g) auxilia nos relacionamentos com instituições e organizações públicas; h) promove identificação e treinamento de fornecedores de serviços qualificados, etc. (KARKOTLI; ARAGÃO, 2004, p. 115).

Os conceitos de diálogo, transparência e prestação de contas são entendidos como o tripé conceitual da accountability. A palavra portuguesa que melhor expressa o significado genérico de accountability é responsabilidade. Etimologicamente o termo responsabilidade deriva dos termos em latim re e spondere, que juntos expressam a ideia de prometer em retorno, em resposta, corresponder. A expressão accountability deriva de ad e computare, que pode ser traduzido como prestar contas a, dar satisfação a, corresponder à expectativa. Segundo Aversa (2006, p. 21, 22), a accountability deve ser estudada "como um termo de base instrumental e a sua aplicação nas organizações deve incidir sobre as estratégias de negócio, que são substancialmente diferentes para as organizações públicas e privadas". O autor argumenta que, para que a accountability "torne-se estratégica, é preciso que a empresa busque a sua participação em torno de uma grande rede de relacionamentos que favoreça a sua RSE (Responsabilidade Social Empresarial) e a sustentabilidade".

Enquanto nas organizações públicas faz-se necessário que exista participação ativa dos cidadãos e o controle social para que ocorram níveis elevados de accountability, nas organizações privadas a accountability "não está condicionada à cidadania ou controle social" (AVERSA, 2006, p. 25). Em uma perspectiva de mercado, diz o autor,

a accountability está, sobretudo, alinhada às estratégias de negócio, e, portanto, precisa ser estimulada pela organização por meio do relacionamento sistemático. Mais do que incidir como um ato político, de poder ou por meio legal, a accountability deve ocorrer por meio do diálogo constante entre a empresa e suas partes interessadas. Ter como objeto de estudo a accountability nas organizações privadas significa abordar a sua instrumentalidade e a sua contribuição para as estratégias de RSE. Accountability só ocorre nessas organizações se for potencializada por meio do diálogo, para que a prestação de contas e transparência, conceitos 
sugeridos para a esfera pública, faça sentido além de uma perspectiva legal, mas contribuindo e orientando as estratégias de relacionamento da empresa (AVERSA, 2006, p. 25).

Assim, pode-se concluir que a adoção da Norma AA 1000 pela Souza Cruz explica sua ênfase, especialmente por meio do Instituto Souza Cruz, na participação em diversas atividades em redes, em encontros, feiras, seminários, envolvendo um crescente número de organizações públicas, privadas e do terceiro setor, bem como sua ênfase nas publicações que abrem espaço para diversos especialistas. A busca de legitimidade social, incluindo certificações e premiações, é funcional à luta pela continuidade dos negócios da empresa. Portanto, sem uma abordagem crítica e paradigmática, a teoria dos stakeholders poderia parecer suficiente para se compreender as estratégias da empresa. A realidade da empresa é entretanto mais complexa e ambivalente do que supõem os defensores de tal teoria.

\section{CRÍTICA À IDEOLOGIA DE RESPONSABILIDADE SOCIAL DA SOUZA CRUZ}

Destacam-se a seguir a síntese de uma dissertação e de dois artigos acadêmicos. O primeiro artigo, da socióloga Paula Johns e da jornalista Anna Cláudia Monteiro (2005, p. 3), é intitulado Responsabilidade social empresarial: a nova face da indústria do tabaco. O texto apresenta entrevistas qualitativas com lideranças de organizações envolvidas com a temática no Brasil, como o GIFE (Grupo de Institutos, Fundações e Empresas), o Instituto Ethos, o Instituto Akatu, o IBASE (Instituto Brasileiro de Análises Socioeconômicas), a própria Souza Cruz, o Instituto Souza Cruz, a empresa Comunicarte (de marketing social), o projeto CEDEJOR, além de visita a três famílias de jovens atendidos por este.

As autoras relatam que Ciro Torres, do IBASE, considera necessário vincular, na avaliação da responsabilidade social, a empresa e seu produto. Para ele empresas fumageiras não podem ser socialmente responsáveis, pois geram impactos sociais e ambientais. Para o Instituto Ethos, há um certo grau de responsabilidade social na Souza Cruz, considerando-se que a empresa investe em programas sociais, ambientais e culturais, apesar de seu produto gerar impactos socioambientais. Ricardo Young, presidente do Conselho do Ethos, chega a dizer 
que a empresa está muito acima da média da prática de responsabilidade social das empresas. Johns e Monteiro (2005, p. 11) discordam, afirmando que um conceito de responsabilidade social "centrado nas relações com stakeholders e dissociado do produto tem limitações graves e não permite uma avaliação mais aprofundada do impacto do produto em si, que é a razão de ser da empresa".

$\mathrm{Na}$ entrevista com Hélio Mattar, presidente do Instituto Akatu, que trabalha com a temática do consumo responsável, as autoras encontram uma argumentação semelhante ao do Instituto Ethos. Mattar entende que a responsabilidade social pode ser dissociada do produto e focalizar o conjunto de relações com os stakeholders. O consumidor é, segundo ele, quem deve ponderar todos os fatores e avaliar o que é mais importante. Esta interpretação disjuntora-redutora da responsabilidade social e a expectativa de que o consumidor seja o agente fundamental na avaliação de tal responsabilidade denotam um enfoque mercadocêntrico ou liberal que encobre ideologicamente a realidade dos impactos socioambientais do tabagismo e da fumicultura.

As autoras informam que o Instituto Akatu estava, na data da entrevista, prestando consultoria a um projeto da Souza Cruz, o que de certa forma esclarece a limitação do enfoque de Mattar. Também no GIFE as autoras encontraram uma percepção tolerante em relação à indústria de tabaco, com uma argumentação que desconsidera o ponto de vista da saúde pública (tanto no que se refere ao tabagismo quanto no que diz respeito à fumicultura).

Johns e Monteiro consideram que a Souza Cruz utiliza o chamado marketing social como forma de estabelecer no imaginário dos públicos com os quais se relaciona uma reputação positiva, de empresa cidadã, responsável, voltada para causas sociais. Observam que a credibilidade das empresas do ramo e o apoio político que tinham foram "seriamente erodidos" pela publicação de "documentos que eram secretos", e que isso só foi possível em razão de processos judiciais nos Estados Unidos desde meados da década de 1990 (JOHNS; MONTEIRO, 2005, p. 16). De fato, obras como The Cigarette Papers, de Glantz et al (1996) mudaram a história da relação entre a indústria de tabaco, o Estado e a sociedade civil, pela contundência e autenticidade de suas denúncias baseadas em documentos que eram internos às empresas, revelando contradições de suas estratégias (pública e privada). Na análise de Johns e Monteiro, a revelação pública da atuação inescrupulosa das empresas do ramo - em atividades como marketing para jovens e 
aumento da dependência química dos consumidores - levou a um ambiente hostil, que as empresas procuram agora compensar com intensa política de envolvimento social, visando conquistar uma imagem positiva.

O médico Paulo Corrêa (2004, p. 17) chega a conclusões semelhantes no artigo intitulado As estratégias do marketing de 'responsabilidade social' da Souza Cruz no Brasil: descrição e análise. Em resumo, o autor afirma que, apesar da proibição de publicidade de cigarros nos meios de comunicação, os consumidores, inclusive menores de idade, continuam expostos às mensagens da indústria de fumo nos pontos-de-venda. Ele denuncia a existência de encartes nos maços de cigarros, como expediente para burlar as restrições à propaganda. Considera que a campanha da Souza Cruz que trata de estimular o consumo com moderação visa construir uma boa imagem pública. Tal estratégia tem efeitos contraditórios sobre os fumantes, que imaginam manter controle sobre o próprio consumo, ainda que desconheçam os processos químicos que os levam à dependência.

A dissertação de mestrado em sociologia política, de Ângela C. Pincelli (2005), é intitulada Trabalho infanto-juvenil na fumicultura e responsabilidade social empresarial: o discurso da Souza Cruz. Em sua pesquisa, a autora procurou analisar o discurso dos programas de responsabilidade da empresa para a eliminação do trabalho infanto-juvenil na produção de fumo, visando compreender os valores que orientam a iniciativa empresarial. Sua análise mostra como a linguagem utilizada coloca a Souza Cruz na posição de ator que luta pela defesa da cidadania para os filhos dos produtores de fumo. O material simbólico utilizado na pesquisa foi um documento de divulgação das ações de responsabilidade social da empresa, publicado pelo Instituto Souza Cruz.

No resumo de sua dissertação, Pincelli escreve o seguinte:

\begin{abstract}
Percebe-se que a ideologia da Souza Cruz no programa de responsabilidade social analisado é a de unir-se ao discurso universal da educação, como fonte de cidadania. Esse discurso retira a fumicultura integrada das suas condições históricas de existência, ocultando, portanto, a estrutura que orienta a subjetividade do agricultor com relação ao trabalho das crianças e adolescentes na plantação de fumo (PINCELLI, 2005).
\end{abstract}

A autora analisa as condições de trabalho características da chamada agricultura familiar e as mudanças provocadas nas famílias de fumicultores ao serem vinculadas ao sistema integrado de produção de fumo, criado pela Souza Cruz em 1918. Com base na já tradicional integração dos fumicultores à lógica industrial da 
empresa, o trabalho familiar, envolvendo crianças, aparece como um suporte para a produtividade exigida pelo industrialismo. Segundo as palavras de Pincelli,

As referências sobre o labor dos filhos dos produtores integrados explicitadas pela Souza Cruz atribuem a culpa e a responsabilidade pela existência daquela modalidade de trabalho à tradição cultural da família produtora rural [...] Embora a empresa atribua o trabalho precoce dos filhos dos produtores de fumo tão somente à tradição de suas práticas sociais, esta mão-de-obra é indispensável para a viabilidade do contrato de integração e, por ser necessária, é naturalizada pelas famílias. O trabalho dos filhos dos produtores na fumicultura tem, portanto, o sentido de dar sustentabilidade ao sistema de integração com a agroindústria. Para a empresa, esta modalidade de trabalho fica sob a única responsabilidade dos pais agricultores, e se constitui em mão-de-obra não computada na fixação do preço do fumo (PINCELLI, 2005, p. 41, 42).

Analisando o discurso empresarial, Pincelli conclui também que ao mesmo tempo em que a Souza Cruz

se apropria do discurso que releva a importância da educação para a cidadania social, ela se dirige aos jovens de famílias produtoras passando a ideia de que a escola tem uma ligação íntima com o trabalho. A empresa tem conhecimento de que os filhos dos produtores rurais trabalham junto com os pais na agricultura familiar. Assim, a ideia de trabalhar na escola não estaria tão longe da ideia de trabalhar na unidade de produção da família, e vice-versa: trabalhar na fumicultura não impede que se trabalhe na escola (PINCELLI, 2005, p. 69).

As conclusões da pesquisadora convergem com as conclusões tanto de Johns e Monteiro (2005) quanto de Correa (2004). A chamada responsabilidade social ganha sentido no contexto de um mercado competitivo, globalizado, com a crise das políticas sociais do Estado contemporâneo sob a hegemonia do neoliberalismo - e a indústria de tabaco é particularmente afetada. Para defender seus negócios das cobranças públicas quanto aos danos à saúde gerados pelo tabaco, as empresas precisam apelar para estratégias sociais, ou melhor, de envolvimento de segmentos da sociedade civil em suas estratégias discursivas. Nesse processo se inclui a defesa da eliminação do trabalho infanto-juvenil na fumicultura.

\section{CONCLUSÕES}

Concluiu-se a partir do exposto que o referencial teórico-epistemológico do pensamento complexo (por meio da distinção e da recursividade entre aspectos 
metateóricos, teóricos e fenômenos) e a abordagem dos estudos críticos em administração permitem compreender a história da Souza Cruz, as faces de sua ideologia de responsabilidade social e as limitações das teorias dos stockholders e dos stakeholders.

A ideologia de responsabilidade social da Souza Cruz é complexa na medida em que o consumo regular de seu produto (cigarro) é causa de doenças e mortes, de redução da produtividade, de restrição da liberdade (dependência química) e, portanto, da cidadania (DELFINO, 2002). Na relação com os fumicultores, a complexidade também é relevante, na medida em que a empresa os envolve em uma dinâmica industrial (por meio do sistema integrado de produção), promovendo desigualdade social e degradação ambiental. Tais impactos socioambientais são dissimulados pelos programas da empresa, que recebem um tratamento ideológico especialmente por meio do Instituto Souza Cruz, da Revista Marco Social e da Norma $A A$ 1000. A Souza Cruz visa atender primordialmente aos interesses dos seus stockholders, mas o faz de tal forma que pareça atender a todos os stakeholders igualmente.

Foi possível perceber o quanto a teoria dos stockholders e a teoria dos stakeholders - disputando o status de teoria dominante em relação à noção de responsabilidade social empresarial - convergem no sentido da racionalização, da padronização, da ideologia. Este estudo, a partir de um enfoque metateórico ou paradigmático, conclui que a ideologia da Souza Cruz situa-se entre as duas abordagens, de maneira ambivalente, oscilando entre a atenção aos seus stockholders e seus diversos stakeholders. As duas abordagens são condicionadas pelo paradigma disjuntor-redutor, pela razão instrumental, o que se evidencia nos programas sociais, culturais e ambientais, à medida que estes são concebidos de maneira instrumentalmente dissociada do produto (cigarro) e de seus efeitos sobre a saúde pública. Viu-se também que o paradigma disjuntor-redutor tem influenciado a percepção de lideranças sociais de organizações como o Instituto Ethos, o Instituto Akatu e o GIFE.

O fato de o próprio Ministério da Justiça reconhecer o Instituto Souza Cruz como Organização da Sociedade Civil de Interesse Público revela que o poder judiciário ainda não dispõe de critérios éticos e de conhecimento científico adequados para tratar da indústria de tabaco, contrariando o Ministério da Justiça, a Organização Mundial de Saúde Pública e até mesmo o Banco Mundial, que desde 
1991 dispõe de política explícita contrária à expansão desta indústria (BOEIRA, 2002).

A Norma AccountAbility 1000 aparece como uma evidência de que a ética, na cultura empresarial da Souza Cruz, é concebida predominantemente como conduta moral e política, restrita a aspectos normativos, funcionais, visando comportamentos padronizados, estratégias discursivas de manutenção de seu status quo. Aliás, as certificações técnicas de um modo geral fazem parte do maior subcampo do conhecimento administrativo, $\mathrm{O}$ das técnicas e metodologias gerenciais, caracterizado pelo predomínio da razão instrumental (RAMOS, 1981) e pela vinculação ao paradigma disjuntor-redutor (por meio do funcionalismo) (FRANÇA FILHO, 2004).

A análise epistemológica (inter e transdisciplinar), histórica, sociológica, assim como a reflexão ética (MORIN, 2005) permitem observar a moral, a política e a estratégia empresariais como circunscritas ao paradigma disjuntor-redutor, com tendência de fechamento de seus sistemas de ideias.

Entretanto, cabe também observar que os programas sociais da Souza Cruz e a própria Norma $A A 1000$ contêm aspectos complexos, ambivalentes. Ainda que sirvam aos interesses de uma empresa que produz enormes impactos sociais e ambientais, tais iniciativas também têm efeitos positivos, especialmente se forem considerados aspectos empíricos, de curto prazo e o ponto de vista de populações marginalizadas atingidas pelos referidos programas. De um ponto de vista crítico, entretanto, é plausível argumentar que tais programas são viabilizados com uma ínfima parcela de investimento dos lucros da empresa e que a ausência do Estado e a própria inércia política da sociedade civil participam, indireta e contraditoriamente, do êxito parcial dos programas. Ou seja, caberia uma autocrítica da sociedade brasileira como um todo, mas especialmente do Estado, por ter permitido o avanço sistemático da fumicultura e o consumo predatório de cigarros como atividades legítimas, lícitas, ainda que insustentáveis do ponto de vista ambiental e ético. Em suma, no contexto de uma grande inércia política, as iniciativas sociais da Souza Cruz revelam-se complexas, ambivalentes, porque beneficiam parcelas minoritárias da sociedade enquanto prejudicam a maior parte da população.

A Convenção-Quadro de Controle do Tabaco (CQCT) representa um novo desafio para a manutenção das estratégias discursivas, ideológicas, das empresas tabaco, mas simultaneamente representa um grande e concreto desafio para a 
sociedade civil, para as prefeituras das regiões fumicultoras, para as famílias de fumicultores, pois, à medida que o consumo de tabaco decrescer, múltiplas alternativas de produção deverão ser criadas - processo que já está em curso, apesar dos inúmeros obstáculos. Até o momento, parece que as estratégias das empresas, aqui representadas pela Souza Cruz, não foram afetadas significativamente pela CQCT (ZIMMERMANN, 2009). Entretanto, o confronto das empresas com a sociedade civil, e não mais apenas com setores de saúde pública (Estado), está em rápida evolução. No Brasil, a Aliança de Controle do Tabagismo (ACTbr) representa um grande esforço de organização da sociedade civil, um início de autocrítica desta sociedade, conforme visto especialmente no artigo de Johns e Monteiro (2005).

A administração pública brasileira, no tratamento das relações entre a indústria de tabaco e seus efeitos socioambientais, precisaria reconhecer a complexidade, as contradições e ambivalências específicas deste setor, evitando a fragmentação setorial e as contradições entre os Ministérios da Justiça, da Saúde, da Agricultura e do Meio Ambiente. Nesse sentido, as contribuições do paradigma da complexidade e da abordagem dos estudos críticos da administração, como subsídio a trabalhos coletivos, inter e transdisciplinares, além de interinstitucionais, parecem ser indispensáveis.

Sem uma abordagem crítica, ética e metateórica da ideologia da responsabilidade social de empresas de tabaco e das teorias dos stakeholders e dos stockholders, é provável que as contradições apontadas neste artigo continuem envolvendo e limitando a efetividade da atuação de ONGs, lideranças da sociedade civil e de setores governamentais. Como conseqüência disso, a implementação da Convenção Quadro de Controle de Tabaco (CQCT) tende a permanecer distante da realidade, como um compromisso assumido mas não cumprido pelo Estado brasileiro. 


\section{REFERÊNCIAS}

ACCOUNTABILITY 1000 (AA 1000). Estrutura: norma, diretrizes e qualificação profissional. Documento básico da norma para uso na contribuição brasileira para a AA 1000. São Paulo: Versão Preliminar, 1999.

ALMEIDA, G. E. G. Fumo: servidão moderna e violação de direitos humanos. Curitiba: Ed. Terra de Direitos, 2005.

ALVES, E. A. Dimensões da responsabilidade social da empresa: uma abordagem desenvolvida a partir da visão de Bowen. Revista de Administração da Universidade de São Paulo (RAUSP), v.38, n.1, p. 37-45, jan/fev/mar., 2003.

ALVESSON, M.; DEETZ, S. Teoria crítica e abordagens pós-modernas para estudos organizacionais. In: (Orgs). CLEGG, S.; HARDY, C.; NORD, W. Handbook de estudos organizacionais. v.1. São Paulo: Atlas, 1998.

ARANHA, Maria L; MARTINS, Maria H. Filosofando: introdução à filosofia. 2 ed. São Paulo: editora Moderna, 1993.

AVERSA, M. O processo de accountability como estratégia de negócio: o caso da Souza Cruz e a implantação da norma AA 1000. 2006. Dissertação (mestrado em administração). Universidade do Estado de Santa Catarina-UDESC, Florianópolis, 2006.

BIOLCHI, M. A. Contexto Rural: A Cadeia Produtiva do Fumo. Revista do

Departamento de Estudos Socioeconômicos (DESER), ano V, n. 5, jul. 2005.

BRASIL. Tabaco e pobreza, um círculo vicioso. A convenção-quadro de controle do tabaco: uma resposta. Ministério da Saúde, Organização Pan-Americana da Saúde. Brasília: Ministério da Saúde, 2004.

CHANLAT, J-F. Ciências sociais e management: reconciliando o econômico e o social. São Paulo: Atlas, 2000.

CLEGG, S; CARTER, C.; KORNBERGER, M. A máquina estratégica: fundamentos epistemológicos e desenvolvimentos em curso. Revista de Administração de Empresas (RAE), v.44, n.4, out/dez, 2004. 
CORREAA, P. C. As estratégias do marketing de responsabilidade social da Souza Cruz no Brasil: descrição e análise. Publicado em 2004 no website da Aliança de Controle do Tabagismo (ACTbr). Disponível em: http://www.actbr.org.br/ Acesso em: 30 jun. 2007.

DAVEL, E.; ALCADIPANI, R. Estudos críticos em administração: a produção científica brasileira nos anos 1990. Revista de Administração de Empresas (RAE), v.43, n.4, out/dez, 2003.

DELFINO, L. Responsabilidade civil e tabagismo no Código de Defesa do Consumidor. Belo Horizonte, Ed. Del Rey, 2002.

ENRIQUEZ, E. Estruturas de legitimidade das organizações, modelos de gestão e ações dos sujeitos individuais e coletivos. In: CHANLAT, J-F.; FACHIN, R.; FISCHER, T. (Orgs.). Análise das organizações: perspectivas latinas. Poder, cultura, subjetividade e vida simbólica. Porto Alegre: Editora da UFRGS, 2007.

ETKIN, J. Gestión de la complejidad en las organizaciones. La estrategia frente a lo imprevisto y lo impensado. México; Oxford, University Press, 2003.

FORTIN, R. Comprendre la complexité. Les Presses de I'Université Laval. Lisboa: Instituto Piaget, 2005.

FRANÇA FILHO, G. C. Para um olhar epistemológico da administração: problematizando o seu objeto. In: SANTOS, Reginaldo S. (Org). A administração política como campo do conhecimento. Salvador: Edições Mandacaru; Universidade Federal da Bahia, 2004.

FREEMANN, R. E. The politics of stakeholder theory: some future directions. Business Ethics Quaterly, v. 4, n. 4, p. 409-422, 1984.

FRIEDMAN, M. The social responsibility of business is increase its profits. New York Times Magazine, New York, 13, Set., 1970.

GLANTZ, S., SLADE, J., BERO, L., HANAUER, P. e BARNES, D. The cigarette papers. Berkeley and Los Angeles: University of California Press, 1996. 
GRIGOROVSKI, P. R. E. Estratégias da Souza Cruz em 101 anos: os desafios para a longevidade saudável. 2004. Dissertação (Mestrado) Instituto COPPEAD de Administração, Universidade Federal do Rio de Janeiro (UFRJ), Rio de Janeiro, 2004.

GUIA EXAME 2004. Guia Exame de boa cidadania corporativa. 5 ed. São Paulo: Editora Abril, dez. 2004.

HAYEK, F. O caminho da servidão. Porto Alegre: Globo, 1967.

IBGE/PETAB. Pesquisa Especial de Tabagismo (PETAB). Instituto Brasileiro de Geografia e Estatística e Ministério de Estado da Saúde, 2008.

INSTITUTO SOUZA CRUZ. Educação para o desenvolvimento humano sustentável. Rio de Janeiro, 2004. Disponível em <http://www.institutosouzacruz.org.br/>. Acesso em: 20 abr. 2009.

JOHNS, P.; MONTEIRO, A. C. Responsabilidade social empresarial: a nova face da indústria do tabaco. Trabalho apresentado pelas autoras na Assembléia Legislativa de São Paulo em 24/11/2005. Publicado em 2005 no website da Aliança de Controle do Tabagismo. Disponível em: http://www.actbr.org.br/ Acesso em: 30 jun. 2007.

KARKOTLI, G.; ARAGÃO, S. D. Responsabilidade social: uma contribuição à gestão transformadora das organizações. Petrópolis: Vozes, 2004.

KUHN, T. The structure of scientific revolutions. Chicago: University of Chicago Press, 1962.

KOFMAN, M. Edgar Morin: from bib brother to fraternity. London: Pluto Press; Lisboa: Instituto Piaget, 1996.

LEVITT, T. The dangers of social responsability. Haward Business Review, p. 4150, set/out, 1958.

MACHADO FILHO, C.; ZYLBERSTAJN, D. A empresa socialmente responsável: o debate e as implicações. Revista de Administração da Universidade de São Paulo (RAUSP), São Paulo, v. 39, n. 3, p. 242-254, jul/ago, 2004. 
MORAIS, F. Souza Cruz 100 anos: um século de qualidade. São Paulo: DBA, 2003.

MORGAN, G. Paradigmas, metáforas e resolução de quebra-cabeças na teoria das organizações. Revista de Administração de Empresas (RAE), v.45, jan/mar, 2005.

MORIN, E. Ciência com consciência. 2 ed. Rio de Janeiro: Bertrand Brasil, 1998.

MORIN, E. Da necessidade de um pensamento complexo. In: MARTINS, F. \& SILVA, J. M. (Orgs.) Para navegar no século XXI. 2 ed. Porto Alegre: Sulina e Edipucrs, 2000.

MORIN, E. O método 4: as idéias - habitat, vida, costumes, organização. Lisboa: Publicações Europa-América, 1991.

MORIN, E. O método 6: ética. Porto Alegre: Sulina, 2005.

MORIN, E. Para sair do século XX. Rio de Janeiro: Nova Fronteira, 1986.

MORIN, E.; PIATELLI-PALMARINI, M. La unidad del hombre como fundamento y aproximación interdisciplinaria. In: APOSTEL, et al. Interdisciplinariedad y ciencias humanas. Madrid: Editorial Tecnos/UNESCO, 1982.

NARDI, J. B. O fumo brasileiro no período colonial: Lavoura, comércio e administração. São Paulo: Brasiliense, 1996.

BOEIRA, S. L. ; KOSLOWSKI, A. Paradigma e disciplina nas perspectivas de Kuhn e Morin. Revista Internacional Interdisciplinar INTERThesis. Florianópolis, v.6, n.1, p. 90-115, jan./jul. 2009.

BOEIRA, S. L.. Atrás da cortina de fumaça. Tabaco, tabagismo e meio ambiente: estratégias da indústria e dilemas da crítica. Itajaí: editora UNIVALI, 2002.

BOEIRA, S. L.; VIEIRA, P. F. H. Estudos organizacionais: dilemas paradigmáticos e abertura interdisciplinar. In.: GODOI, C. K.; BANDEIRA-DE-MELLO, R.; SILVA, A. B. (Orgs.) Pesquisa qualitativa em estudos organizacionais: paradigmas, estratégias e métodos. São Paulo: Saraiva, 2006. 
NICOLESCU, B. O manifesto da transdisciplinaridade. São Paulo: Ed. Triom, 1999.

OMS. Tabaquismo y salud en las Américas. Informe de la Cirujana General, 1992, en colaboración con la Organización Panamericana de la Salud.: Organización Mundial de la Salud, 1992.

OMS. Relatório da OMS sobre a epidemia de tabaco global. In: INSTITUTO NACIONAL DO CÂNCER. Publicações sobre tabagismo. 22 de fevereiro de 2008. Disponível em: http://www.inca.gov.br/. Acesso em 26 abr. 2009. Texto original disponível em: www.who.int/tabaco/mpower .

PALAZZO, G.; RICHTER, U. CSR business as usual? The case of the tobacco industry. Journal of Business Ethics, v.61, n.4, p. 387-401, nov. 2005.

PAULILO, M. I. S. Produtor e agroindústria: consensos e dissensos (o caso de Santa Catarina). Florianópolis: UFSC, 1990.

PENA, R. Ética y estrategia en un marco teórico referencial de la ética de negocios. Revista de Administração Contemporânea (RAC), Edição Especial, v.8, p. 229252, 2004.

PINCELLI, A. C. Trabalho infanto-juvenil na fumicultura e responsabilidade social empresarial: o discurso da Souza Cruz. 2005. Dissertação ( Mestrado em sociologias política) Centro de Ciências Humanas, Universidade Federal de Santa Catarina. Florianópolis, 2005.

POSTMAN, N. Tecnopólio: a rendição da cultura à tecnologia. São Paulo: Nobel, 1994.

RAMOS, A.G. A nova ciência das organizações: uma reconceituação da riqueza das nações. Rio de Janeiro: FGV, 1981.

RODRÍGUEZ, A. S. A fumicultura e a questão ambiental: o perfil do fumicultor em Restinga Seca-RS. 1996. Dissertação ( mestrado em extensão rural) Centro de Ciências Rurais: Universidade Federal de Santa Maria, Santa Maria, 1996.

SANTOS, B. S. Pela mão de Alice. O social e o político na pós-modernidade. São Paulo: Cortez, 1995. 
SCHNAPPER, D. Os limites da expressão "empresa cidadã". In: MORIN, E., et al. A sociedade em busca de valores: para fugir à alternativa entre o cepticismo e o dogmatismo. Lisboa: Instituto Piaget, 1996.

SILVEIRA, R. L. L. A produção da periferia urbana em Santa Cruz do Sul-RS: o lugar dos safristas na terra do fumo. 1997. Dissertação (Mestrado em Geografia) Centro de Filosofia e Ciências Humanas: Universidade Federal de Santa Catarina. Florianópolis, 1997.

SKLAIR, L. Sociologia do sistema global. Petrópolis: Vozes, 1995.

SOUZA CRUZ. Álbum oitenta anos de Brasil (1903-1983). Edição da Souza Cruz, 1983.

SOUZA CRUZ. Relatório de Atividades 2006. Rio de Janeiro: Souza Cruz, 2006.

STONER, J. A .F; FREMMAN, R. E. Administração. Rio de Janeiro: LTC, 1999.

THOMPSON, J. B. Ideologia e cultura moderna: teoria social crítica na era dos meios de comunicação. Petrópolis: Vozes, 1995.

VASCONCELOS, E. M. Complexidade e pesquisa interdisciplinar. Epistemologia e metodologia operativa. Petrópolis: Vozes, 2002.

VOGT, O. P. A produção de fumo em Santa Cruz do Sul - RS, 1849-1993. Santa Cruz do Sul: Edunisc, 1997.

WEBER, M. Le savant e le politique. Paris: Union Générale d’Éditions, 1959.

XAVIER; A. M.; SOUZA, W.J. Responsabilidade social empresarial: estudo teóricoempírico à luz dos Instrumentos Ethos. Encontro da ANPAD, 28, 2004, Curitiba. Anais... Curitiba, 2004. 1 CD-ROM.

ZIMMERMANN, M. Convenção-Quadro para o Controle do Tabaco: perspectivas para a fumicultura na região sul. 2009. Dissertação (Mestrado em Gestão de Políticas Públicas) Centro de Ciências Sociais e Jurídicas: Universidade do Vale do Itajaí (UNIVALI). Itajaí, 2009.

Artigo: Recebido em: 21/03/2010 Aceito em: 29/03/2010

R. Inter. Interdisc. INTERthesis, Florianópolis, v.7, n.2, p. 276-315, jul/dez. 2010 